\title{
Parent Factors Related to Social Intervention Outcomes: Examining Immediate and Delayed Responders
}

\author{
Tina L. Stanton-Chapman (Corresponding author) \\ Curry School of Education, University of Virginia \\ 417 Emmet Street South, Charlottesville, VA 22904-4273, USA \\ Tel: 1-434-982-2638 E-mail: stantonchapman@virginia.edu \\ James L. Peugh \\ Cincinnati Children's Hospital \& Medical Center \\ MLC 3015, 3333 Burnet Avenue, Cincinnati, OH 45229-3026, USA \\ Tel: 1-513-803-5170 E-mail: james.peugh@cchmc.org \\ Erik W. Carter \\ Department of Special Education, Peabody \#328 \\ Vanderbilt University \\ Nashville, TN 37203-5721, USA \\ Tel: 1-615-322-8150 E-mail: erik.carter@vanderbilt.edu
}

\author{
Kristen Roorbach Jamison \\ Center for the Advanced Study of Teaching and Learning \\ University of Virginia \\ 350 Old Ivy Way, Charlottesville, VA 22903, USA
}

Tel: 1 434-243-3733 E-mail: kjamison@virginia.edu

Received: February 20, $2012 \quad$ Accepted: April 5, $2012 \quad$ Published: May 1, 2012

doi:10.5539/jedp.v2n1p2 URL: http://dx.doi.org/10.5539/jedp.v2n1p2

\begin{abstract}
The purpose of this study was to explore several family-related factors that may be associated with treatment response to an evidence-based social communication intervention targeting preschoolers with disabilities or at-risk. We used multilevel modeling to conduct retrospective analyses of data collected across a series of single-case intervention studies. Forty-six preschoolers participated in the study. The results of the positive peer interactions analyses indicated that children from married, separated, or widowed homes and children with mothers with high maternal education levels tended to interact more positively with their peers and decreased in their amount of play verbalizations over time relative to children whose parents were divorced or had low maternal education levels. Similar data patterns were found for both the immediate responders (e.g., children who make immediate progress once an intervention program has begun) and delayed responders (e.g., children who make changes in behavior after receiving a few or several intervention sessions).
\end{abstract}

Keywords: Preschool, HLM, Social skills, Intervention

\section{Introduction}

One key element in establishing a set of evidence-based practices for promoting peer relationships among 
preschoolers involves recognizing the need for the individualization of treatment. A compelling knowledge base should enable practitioners and researchers to better identify which intervention strategies work with which students (Horner et al., 2005). This approach involves moving beyond advocating for a single intervention approach for all children, and instead requires determining when and with whom particular intervention approaches are most likely to be effective (Sherer \& Schreibman, 2005). Indeed, recent reviews of published studies reveal that substantial variability exists in children's social-related outcomes within and across intervention studies, suggesting that individual factors may be influencing efficacy (Carter, Sisco, Chung, \& Stanton-Chapman, in press; Reichow \& Volkmar, 2010). Although early intervention teams should attempt to better match procedures to children (Prizant \& Wetherby, 1998), the empirical literature currently provides limited guidance regarding which individual factors may be important for these teams to consider.

One necessary step in determining whether and how an intervention works for particular children involves defining and determining the profiles of immediate responders, delayed responders, and non-responders. An extensive body of research - primarily in the areas of academic interventions (e.g., math and reading) - has focused on the issue of who does and does not respond to intervention efforts. Non-responders have been defined as children who do not make adequate progress despite receiving an evidence-based intervention (McMaster, Fuchs, Fuchs, \& Compton, 2005). Immediate responders have been defined as children who make immediate progress once an intervention program has begun, and delayed responders are defined as children who make changes in behavior after receiving a few or several intervention sessions (McMaster et al.). This area of research has provided many insights into salient factors that distinguish those students with or at-risk for disabilities who do and do not benefit from specific intervention efforts. An exploration of how specific factors are associated with differential outcomes could help practitioners better tailor intervention efforts to maximize social outcomes. In addition, identifying individual characteristics that predict responsiveness to treatment could improve screening measures and inform the selection of the most appropriate early and intensive intervention for children with certain characteristics (Al Otaiba \& Fuchs, 2002).

One promising social communication intervention for preschoolers with or at-risk for disabilities is shared-storybook reading (e.g., Stanton-Chapman, 2005; Stanton-Chapman, Denning, \& Jamison, 2008, 2010). This approach involves teaching children four social communication skills (i.e., initiating, responding, name use, turn taking), providing an advanced play organizer (e.g., teaching target vocabulary words, assigning children play roles, reading the storybook, play planning), structuring play sessions within a dramatic theme, and engaging children in a brief review session to review their performance. Over the past four years, we have conducted a series of single-case intervention studies involving a total of 46 children attending high-poverty preschools to evaluate the efficacy of this shared-storybook reading on children's positive peer interactions and verbal play (e.g., Stanton-Chapman, Jamison, \& Denning, 2008; Stanton-Chapman, Kaiser, Vijay, \& Chapman, 2008; Stanton-Chapman, Kaiser, \& Wolery, 2006; Stanton-Chapman \& Snell, In Press). Although this intervention has produced immediate and pronounced social-related improvements for the majority of participating children, some participants' gains were delayed. Our interest now turns to understanding those factors that may account for differential intervention effects across these children.

Research suggests that family-related factors may contribute to variations in the efficacy of social communication interventions. The marital status and highest education of parents - although less proximal —are two relevant variables. Several researchers have indicated that single parent households and low maternal education (a common marker for low socioeconomic status; Chomitz, Cheung, \& Lieberman, 1995) are associated with social interaction difficulties in young children postulating that these factors diminish a parent's capacity for consistent and involved parenting (Pungello et al., 2010; Wilson, Hurtt, Shaw, Dishion, \& Gardner, 2009). As for early language development, mothers in higher SES households may be more intensely involved in daily interactions offering rich opportunities for interaction (Westerlund \& Lagerberg, 2008), such as inviting the child to participate in conversations and asking the child to describe and explain his/her activities. Conversely, mothers from low SES households tend to use more directives (e.g., do this, do that) that are not related to the child's current activity and use more yes/no questions (Hoff-Ginsberg, 1991). These effects may be magnified if one examines the cumulative effects of multiple risk factors on the social communication skills of young children. For example, Reyno and McGarth (2006) found that children living within families that were coping with multiple adversities - such as single-parent homes, lower income, and low maternal education - had higher rates of non-responders within an intervention focused on reducing oppositional behavior.

The purpose of this study was to explore several family-related factors that may be associated with treatment response to an evidence-based social communication intervention targeting preschoolers in Head Start settings. Understanding the family-related risk factors that may be associated with treatment response to intervention may 
allow for increased theoretical understanding of the etiology of social communication difficulties and allow for appropriate intervention selection for target populations. We used multilevel modeling to conduct retrospective analyses of data collected across a series of single-case intervention studies. Our first aim was to examine the effects of the social communication intervention on the number of positive interactions between peers across intervention conditions. Our second aim was to examine the effects of the social communication intervention on the number of play verbalizations across conditions. Finally, we were interested in identifying characteristics of children who are immediate responders, delayed responders, and non-responders in relation to both sets of outcomes.

\section{Method}

\subsection{Participants}

Inclusion criteria. We have implemented shared-storybook reading interventions with 46 preschool children within a series of single-case research designs. All participants in the current study took part in a social communication intervention targeting children with language delays, social skills delays, and/or problem behaviors. Participants for these studies were three, four, or five years old at the introduction of the study and were rated by their classroom teachers as having low rates of social interactions (e.g., initiations, responses, turn-takes) during dyadic or group play. In addition, participants in these studies had to meet one or more of the following criteria: (a) they scored at least one standard deviation below the normative mean (a total standard score of 80 or below) on the total language score of the Preschool Language Scale-4 (PLS-4; Zimmerman \& Pond, 2002); (b) they were rated by teachers as having clinical levels of problem behavior (i.e., a total score of 60 or above on either the internalizing or externalizing scale) on the Child Behavior Checklist-Teacher Form (CTRF; Achenbach, 1997); and/or (c) they demonstrated poor social skills (a total social skill subscale score of 85 or below) on the Social Skills Rating System-Teacher Form (SSRS; Gresham \& Elliott, 1992).

Sample. Forty-six children met the selection criteria for inclusion in the current study. Their ages ranged from 36 months to 70 months $(M=52$ months). Ten children (22\%) did not have an Individualized Education Program (IEP), but were eligible for the study based on teacher recommendation or their low language, social skills, and problem behavior assessment scores. All children were from low socioeconomic backgrounds, as evidenced by Head Start status. Table 1 presents the demographic information for the participant sample. The children were assigned to dyads based on a specified protocol. First, the children had to meet the criteria for participant inclusion. Second, both children had to be available during free play on the same day and times. Finally, attempts were made to pair the children by age. Preliminary analyses indicated that the participants did not differ despite differences in chronological age, developmental age, and level of functioning in the areas of social, emotional, communicative, and intellectual functioning.

Identifying children who are immediate responders, delayed responders and non-responders. The effects of the social communication intervention were tested using a series of multiple baseline designs across participants at three rural elementary schools. Visual analysis of repeated measures data across baseline and intervention conditions was used to categorize children as either immediate or delayed responders in positive social interactions and play verbalization categories. These decisions were based on visual inspection of mean, level, trend, and variability within and between baseline and intervention phases. Specifically, we calculated the median level of data in the baseline and intervention phases by sequencing the data-point values from low to high. If there were an odd number of data points in a phase, the middle data-point was considered the median. If there was an even number of data points in a baseline or intervention phase, the median was the average of the two middle values. A stability criterion of $20 \%$ was established meaning that a data series was considered stable if $80 \%$ of the data points fell on or within $20 \%$ of the median level (Gast \& Spriggs, 2010). For children who were immediate responders $(n=37)$, data patterns in positive interactions and play verbalizations indicated an immediate change in level and an accelerating trend within the first three intervention sessions. For children who were delayed responders $(n=9)$, improvements in level and trend were not seen until five or more intervention sessions were completed. Since all participants responded to the intervention at some point during implementation, a "non-responder" category was not necessary.

\subsection{Setting}

All three elementary schools were high-poverty, Title I schools serving children with and without disabilities in inclusive preschool classrooms. The classrooms were collaborative in nature-meaning the program provided services to children at-risk for developmental disabilities (Head Start) and children with special needs (early childhood special education; ECSE). All sessions took place in empty classrooms used for small-group activities and meetings. 


\subsection{Study Personnel}

Three child interventionists conducted the baseline and intervention sessions. All had educational degrees in early intervention and/or special education and between 2 and 12 years of experience teaching children at-risk and children with disabilities. Transcribers and coders for observational data, treatment fidelity measures, and reliability coding were graduate students in an ECSE master's program. All research staff held Bachelor's degrees in psychology and had practicum hours in early childhood, at-risk, and ECSE classrooms. To reduce potential bias, all transcribers and coders were blind to the study outcomes.

\subsection{Description of Intervention Program}

The social communication intervention was a program that emphasized social pragmatic skills (e.g., initiations, responses, turn-taking, appropriately obtaining a peer's attention) and play skills (e.g., sharing, not monopolizing play, proximity to peer)-skills strongly associated with school readiness and later school achievement (Lopez, Tarullo, Forness, \& Boyce, 2000; Missall \& Hojnoski, 2008). The intervention program was consistent across all years of the study.

Play materials. Play materials used during the baseline and intervention conditions were based on five dramatic play themes - grocery store, doctor, construction, animal doctor, and hair salon/barber. Each dramatic play theme had an accompanying storybook that provided instruction on the intervention's target behaviors. The storybooks were designed to include pictures of participating children and the exact materials and props used during the intervention sessions. The books were computer-generated using a digital camera and a template for the book format (interventionists inserted pictures of study participants into the storybooks and entered the names of the children in the story's text). The thematic play materials were similar to the types of toys and activities available in preschool classrooms. Play materials matched pictures in the storybook.

Intervention description. Intervention sessions were conducted one to three times a week and were approximately 20 to 25 -min in length. Each session with a particular dyad used one of the five dramatic play themes and cycled through all of the themes before repeating the themes for a second time. Each intervention session had three parts: an advanced play organizer, a play session, and a review session. Intervention sessions were videotaped using a digital camcorder on a tripod. The intervention was used to teach the following social communication skills: (a) talk to your friends (initiations): verbally initiating a conversation or play episode with a peer (e.g., intelligible utterances directed to a peer, within speaking distance of a peer); (b) listen then respond to what your friend says (responding): verbally responding to peer verbal initiations (e.g., topic related, intelligible, directed to the peer, not interrupting your friend while he or she is talking, not talking at the same time as your friend); (c) use your friend's name: stating a peer's name to gain his or her attention before talking with him or her; and (d) take a turn and give your friend a turn (turn-taking): taking an appropriate number and length of turns in conversation or play (e.g., sufficient turns, not dominating conversation, pausing for a peer to talk, taking turns to maintain conversation or play, asking for clarification, providing clarification, not interrupting a peer when he or she is talking).

The advanced play organizer component was approximately 10 min in length and had four parts: (a) instruction of target vocabulary words; (b) instruction of the roles for each theme; (c) reading the storybook and instruction of the social communication strategies; and (d) play planning. The children then played with the thematic materials for $10 \mathrm{~min}$. Interventionists assisted children, as needed, with the specific costumes and items needed for their play roles. The interventionist sat in the play area with the children but did not get directly involved in their play unless interactions were not taking place. At the conclusion of the play session, the children moved away from the play area and reviewed their performance in the play session with the interventionist. The review session was approximately $5 \mathrm{~min}$ in length and the interventionist reviewed the thematic roles, use of target vocabulary words, and use of the social communication strategies.

\subsection{Observational Measures and Inter-observer Agreement}

All 10-min baseline sessions and the 10-min intervention play sessions were analyzed and data collection procedures for both conditions followed four steps. First, videotaped sessions were downloaded from the video camera onto the computer. Second, the baseline and play sessions were transcribed word-for-word by research staff. Research staff were trained to a criterion of $90 \%$ agreement for five successive practice sessions. Third, the interventionist verified the transcripts of their baseline and intervention sessions for accuracy. Finally, the videotapes and transcripts of the sessions were reviewed and were coded by trained research staff using the Peer Language and Behavior Code (PLBC; Stanton-Chapman, Kaiser, Vijay, \& Craig-Unkefer, 2003). Similar to transcription procedures, coders were trained to a criterion of $90 \%$ for five successive practice sessions. 
The PLBC was employed to measure verbal and nonverbal interactions between children with or without adult prompting during the play session. Interactions were scored continuously and the frequency of occurrences were tallied for each respective session. Data were collected on two types of verbal and nonverbal interactions - positive interactions and play verbalizations. Positive interactions were situations when the child made a verbal or nonverbal request to the peer to engage in a different play activity, a variation of the current play activity, or to obtain an object. It also included situations when the child made an appropriate verbalization to a peer that could not be characterized as requesting, but rather as a comment, play organizing statement, or share (e.g., saying "I put shampoo in her hair" during a hair salon/barber play session). Play verbalizations were comments or requests directed to an inanimate play object or toy. The attention of the child was directed toward the toy or object, and the content of the play verbalization was specifically directed to the toy. This also included instances where the child is speaking to himself or herself and not to the peer (e.g., a child says "you are really hungry doggie" to the stuffed animal during an animal doctor play session).

Interobserver agreement was calculated on the PLBC. One research staff member coded all baseline and intervention sessions. To assess reliability, a second research staff member coded a random selection of $20 \%$ of the baseline and intervention sessions. Reliability observations were equally distributed across all 23 dyads and experimental conditions. Using Storybook Rely (Tapp, 2003), a sequential comparison of the coded data was made on a point-by-point basis. The program scored an agreement if both coded a behavior within a $5 \mathrm{~s}$ time window and scored a disagreement if they differed on an identified behavior or coded the same behavior but did not meet the $5 \mathrm{~s}$ time window. Reliability was assessed using an exact agreement formula in which the total number of agreements was divided by the total number of agreements plus disagreements and multiplied by $100 \%$. Interobserver agreement was high across all dyads, measures, and experimental conditions. Interobserver agreement for positive interactions averaged 95\% (range, 83-100\%) during baseline conditions and averaged 92\% (range, $79-100 \%$ ) during intervention conditions. For play verbalizations, interobserver agreement averaged 97\% (range, $91-100 \%$ ) for baseline conditions and 98\% (range, $80-100 \%$ ) for intervention conditions.

\subsection{Treatment Fidelity}

Fidelity of treatment checklists were completed for $20 \%$ of randomly selected intervention sessions (Stanton-Chapman, 2005). Videotapes of the entire session were viewed and scored by a research staff member other than the interventionist. Criterion for fidelity of treatment was the correct completion of $95 \%$ of the 25 prescribed items. Reaching criterion level indicated that the interventionist organized, described, and demonstrated the toys used in the play theme, read the storybook, discussed and modeled the use of the social communication strategies, attended to the children's activities during the play session, and reviewed the children's use of the social communication strategies and target vocabulary words in the review session. The average score for treatment fidelity for preparation of intervention materials, advanced play organizer, and review sessions was $98 \%$ (range $=95-100 \%$ ).

\subsection{Data Analysis Procedures}

In recent years, the value of using hierarchical linear modeling (HLM) approaches in combining and analyzing data from single-subject designs has been discussed (e.g., Campbell \& Herzinger, 2009; Kratochwill et al., 2010; Roudenbush \& Bryk, 2002; Shadish, Rindskopf, \& Hedges, 2008; Van den Noorgate \& Onghena, 2003). The essential idea of HLM modeling using single subject data is to formulate two models; one that represents individual change and one that represents change across individuals. This allows both group and individual parameters to be estimated and tested efficiently using all data available (Van den Noorgate \& Onghena, 2003). Roudenbush and Bryk (2002) highlight several advantages in using HLM analyses to explore single subject data: (a) HLM tests for change over time for level and trend, and consequently, level and trend together, (b) it accounts for the initial level of the target behavior which allows it to be useable across a wide range of designs and settings, (c) participants receiving the same intervention but showing different initial levels of behavior can still be comparable, (d) it is useable on almost every single-subject design including multiple baseline design - the design utilized in the current study, and (e) it can accommodate unequal intervals between measurements.

The observation data collected from the PLBC (positive interactions and play verbalizations) provided a frequency count of behaviors across the 10-min play sessions for baseline and intervention sessions. Children were paired into dyads based on several important socioeconomic, demographic, and individual achievement characteristics prior to observational testing. We were interested in how a set of individual level family variable were related to a set of individual child level outcome variables. For this reason, the dyads were treated as indistinguishable (Kenny, Kashy, \& Cook, 2006) in all analyses (no theoretically relevant variable could meaningfully distinguish "child \#1" from "child \#2" within each dyad; Kenny \& Ledermann, 2010). With 
respect to both response variables (positive play interactions and play verbalizations), our statistical power was sufficient to reject the null hypothesis for several non-linear cross-level HLM interactions.

Longitudinal and cross-sectional analyses were conducted for the positive peer interactions and verbal play episodes response variables $(Y)$. A data-driven, model-building approach (Peugh, 2010) was used for the longitudinal HLM analyses based on the following general model (Atkins, 2005; Laurenceau \& Bolger, 2005):

$$
\begin{gathered}
Y_{\text {tid }}=\beta_{0 i d}+\beta_{1 i d}\left(\text { Time }_{\text {tid }}-1\right)+\varepsilon_{\text {tid }} \\
\beta_{0 i d}=\gamma_{000}+u_{0 i d} \\
\beta_{1 i d}=\gamma_{100}+u_{1 i d}
\end{gathered}
$$

Response variable $(Y)$ data collected over $t$ longitudinal measurement occasions from $i$ children paired into $d$ indistinguishable dyads $\left(Y_{t i d}\right)$ was modeled as a function of an expected response variable score at the first measurement occasion $\left(\gamma_{000}\right)$, and an average response variable change between each assessment time points $\left(\gamma_{000}\right)$, across all dyads. The expected response variable score at the first measurement occasion $\left(\gamma_{000}\right)$ was allowed to vary across dyads in all analyses (i.e., the $u_{0 i d}$ variance was estimated); whether changes in the response variable over time varied significantly across dyads (i.e., whether the $u_{\text {lid }}$ variance was estimated) was tested for both response variables, as explained below. The 'Time' variable was an integer value that indicated measurement occasion and was centered (Mehta \& West, 2000) at the first assessment occasion, as shown in Equation 1.

The model-building approach used for the longitudinal analyses consisted first of building the level-1 model (shown in Equation 1) followed by building the level-2 models (shown in Equations 2 and 3). Building the level-1 model involved first testing whether the average response variable change over time $\left(\gamma_{000}\right)$ varied significantly across dyads (i.e., whether the $u_{\text {lid }}$ variance was significant) using likelihood ratio nested model testing. Specifically, the difference in the deviance $(-2 *$ model $\log$ likelihood $[\log L]$ value) statistics between a model that allowed slope variation (i.e., estimated the $u_{\text {lid }}$ variance; full model) and one that did not (reduced model) was computed as follows:

$$
\left(-2 \log L_{\text {Reduced Model }}\right)-\left(-2 \log L_{\text {FullModel }}\right)
$$

Building the level-1 model also involved adding a quadratic term (i.e., Time $^{2}$ ) to Equation 1 to test for possible non-linear response variable changes over time. A model that included a quadratic term (full model) was tested against a model that did not include a quadratic term (reduced model) using Equation 4 above.

Building the level-2 model involved testing three groups of covariates for significant relationships to each response variable. First, the child covariates of verbal expression and comprehension, and whether children's response to the intervention was immediate or delayed, were tested first. Two sets of parent covariates were subsequently tested: binary variables that indicated the marital status of a child's parents (i.e., single, separated, divorced, or widowed) were tested for a significant relationship to the response variable, with married parents served as the baseline comparison category, and binary parental education variables (some high school, a high school diploma, or some college credits) were similarly tested for a significant relationship to the response variables with $8^{\text {th }}$ grade or less education serving as the baseline comparison category. The three covariate sets were added to Equation 2, and added to Equation 3 only if a level-1 nested model test showed that the expected response variable change over time varied significantly across dyads. For each of the three sets of covariates, the model that included that covariate set (full model) was tested against the previously best-fitting model that did not contain that set of covariates (reduced model) using Equation 4. For all level-1 and level-2 likelihood ratio nested model tests, the results of Equation 4 were tested against a chi-square distribution at degrees of freedom equal to the difference in the number of estimated parameters between the full and reduced models under comparison.

Cross-sectional actor-partner interdependence models (APIM; cf., Kenny, 1996) were estimated to test for significant relationships between the covariates of verbal comprehension (Comp) and verbal expression (Exp) and the response variable word diversity (Div).

$$
\begin{aligned}
& \operatorname{Div}_{\text {Child\#1 }}=\beta_{0}+\beta_{\text {Actor }}\left(\operatorname{Comp}_{\text {Child\#1 }}\right)+\beta_{\text {Partner }}\left(\operatorname{Comp}_{\text {Child } 22}\right)+\varepsilon_{\text {Child\#1 }} \\
& \operatorname{Div}_{\text {Child } \# 2}=\beta_{0}+\beta_{\text {Actor }}\left(\operatorname{Comp}_{\text {Child } 2}\right)+\beta_{\text {Partner }}\left(\operatorname{Comp}_{\text {Child } \# 1}\right)+\varepsilon_{\text {Child\#2 }} \\
& D i v_{\text {Child } \# 1}=\beta_{0}+\beta_{\text {Actor }}\left(\operatorname{Exp}_{\text {Child } \# 1}\right)+\beta_{\text {Partner }}\left(\operatorname{Exp}_{\text {Child } \# 2}\right)+\varepsilon_{\text {Child } \# 1} \\
& \operatorname{Div}_{\text {Child } \# 2}=\beta_{0}+\beta_{\text {Actor }}\left(\operatorname{Exp}_{\text {Child } 2}\right)+\beta_{\text {Partner }}\left(\operatorname{Exp}_{\text {Child } \# 1}\right)+\varepsilon_{\text {Child } \# 2}
\end{aligned}
$$

The APIMs in Equations 4 and 5 test for "actor" effects (e.g., a significant relationship between child \#1's verbal 
comprehension or verbal expression and child \#1's word diversity) and "partner" effects (e.g., a significant relationship between child \#1's verbal comprehension or verbal expression and child \#2's word diversity).

The MIXED command in SPSS Version 18.0 was used to perform all longitudinal growth model and cross-sectional APIM analyses. There was no missing data for any variable at any assessment occasion. All level-2 continuous covariates were grand-mean centered for all longitudinal and cross-sectional models prior to analysis (Enders \& Tofighi, 2007).

\section{Results}

\subsection{Positive Peer Interactions}

The longitudinal growth modeling results for the response variable positive peer interactions are summarized in Table 2.

Building the level-1 model. The conditional growth model shown in Equations 1-3 was estimated (excluding the $u_{\text {Iid }}$ term) and the results are shown in the second column of Table two. Specifically, results showed a significantly non-zero grand mean positive peer interaction score $\left(\gamma_{000}=4.20, p<.01\right)$ at the first assessment occasion that increased roughly $1 / 3$ of a point at each subsequent assessment occasion, on average $\left(\gamma_{000}=.31, p\right.$ $<.01$ ). Variance component estimates further showed: (a) significant observed versus predicted positive peer interaction variation $\left(\sigma^{2}=19.88, p<.01\right)$, (b) a significant observed variable residual covariance $\left(\sigma_{01}=6.87, p\right.$ $<.01$ ), and (c) significant positive peer interaction score variation across dyads at the first assessment $\left(\tau_{00}=14.58\right.$, $p<.01)$. The conditional growth model shown in Equations 1-3 was next estimated allowing changes in positive peer interaction scores over time to vary across dyads (i.e., the $u_{\text {Iid }}$ term was included). As shown in the third column of Table 2, change in positive peer interaction scores varied slightly, but significantly, across child dyads $\left(\tau_{11}=.06, p<.05\right)$. The intercept/slope covariance was non-significant $\left(\tau_{01}=-.17\right)$, indicating no relationship between initial positive peer interactions and change in positive peer interactions over time. A nested model test (i.e. 5461.88-5429.37 $=32.51 ; \chi^{2}[7-5=2]=32.51, p<.01$ ) confirmed that allowing changes in positive peer interactions across time to vary across dyads resulted in a significant improvement in model fit. A quadratic term (i.e., $\gamma_{200}$; Time $^{2}$ ) was then added to the model that allowed change in positive peer interaction scores over time to vary across dyads to test for the presence of a non-linear trend; results are shown in column four of Table 2 . The quadratic term estimate $\left(\gamma_{200}=-.02, p<.05\right)$ showed a significant negative deviation from a linear increase in positive peer interactions over time. A second nested model test (i.e., 5429.37-5412.48 $=16.89 ; \chi^{2}[8-7=1]=$ $16.89, p<.01$ ) showed that adding the quadratic term also significantly improved model fit.

Building the level-2 model. None of the child covariates were significantly related to positive peer interactions and were not considered further. The marital status covariates were of greater theoretical interest and were entered first into Equations 2 and 3 (because changes in positive peer interaction scores over time varied across dyads) of the previous model that allowed quadratic change in positive peer interactions. Results are shown in the fifth column of Table 2 ; separated $(1.87, p<.01)$ parental status was significantly and positively related to positive peer interactions at the first assessment, while single parent status $(-1.66, p<.01)$ was significantly and negatively related to positive peer interactions at the first assessment. Further results showed two significant cross-level interactions: compared to married parents, children whose parents were widowed $(.29, p<.05)$ showed significantly greater increases in positive peer interactions over time, while children whose parents were divorced $(-.24, p<.05)$ showed significantly fewer positive peer interactions over time, as shown graphically in Figure 1 (Aiken \& West, 1991). A nested model test showed that adding the four parental marital status covariates and the two cross-level interactions produced a significant improvement in model fit (i.e., $\left.5412.48-5388.24=24.24 ; \chi^{2}[14-8=6]=24.24, p<.01\right)$.

The parental education binary covariates were next entered into the model and tests for significant educational status by time interactions were conducted. All results are shown in the sixth column of Table 2. Children showed significantly more positive peer interactions at the first assessment point if parents had some high school education $(2.78, p<.01)$ compared to parents with an $8^{\text {th }}$ grade education or less. Further, two significant cross-level interactions were found: children showed significantly more positive peer interactions over time if parents had a high school diploma $(.31, p<.01)$ or some college credits $(.24, p<.01)$ compared to parents with an $8^{\text {th }}$ grade education or less, as shown graphically in Figure 2. A nested model test further showed that the addition of the three parental educational status covariates and the two cross-level interactions also produced a significant increase in model fit (i.e., 5388.24-5352.79=35.45; $\chi^{2}[19-14=5]=35.45, p<.01$ ).

\subsection{Verbal Play Episodes}

The longitudinal growth modeling results for the response variable verbal play episodes are summarized in Table 3. 
Building the level-1 model. The conditional growth model shown in Equations 1-3 was estimated (with the $u_{\text {lid }}$ term initially excluded). The results of this analysis are shown in the second column of Table 3: children had a significantly non-zero grand mean verbal play episodes score $\left(\gamma_{000}=9.57, p<.01\right)$ at the first assessment that significantly decreased over time $\left(\gamma_{100}=.40 ; p<.01\right)$. Variance component estimates further showed: (a) significant observed versus predicted verbal play episodes variance over time $\left(\sigma^{2}=38.40, p<.01\right)$, (b) a non-significant observed variable residual covariance $\left(\sigma_{01}=-0.42, p>.05\right)$, and (c) significant variation in verbal play episodes across dyads at the first assessment $\left(\tau_{00}=12.98, p<.01\right)$. The conditional model was also estimated to test whether changes in verbal play episodes over time varied across dyads (i.e., the $u_{\text {Iid }}$ term was included); the results showed a non-significant slope variance $\left(\tau_{11}\right)$ estimate. A quadratic term (i.e., $\gamma_{200}$; Time ${ }^{2}$ ) was then added to test for the presence of non-linear change in verbal play episodes; results showed the non-linear trend parameter estimate was also non-significant.

Building the level-2 model. As shown in the third column of Table 2, the child covariate Pre-PLS4 (which combine verbal expression and comprehension indices) was significantly and negatively $(-.04, p<.05)$ related to verbal play episodes. A nested model test (i.e., 5797.79-5792.32 $=5.47 ; \chi^{2}[6-5=1]=5.47, p<.05$ ) showed adding PrePLS4 scores to a model containing linear time as a fixed effect significantly improved model fit.

Parental marital status covariates were added to a model containing PrePLS4 scores. As shown in the fourth column of Table 3 , divorce $(2.47, p<.01)$ was significantly and positively related to increased episodes of verbal play at the first assessment point. A nested model test (i.e., 5792.32-5786.19=6.13; $\chi^{2}[7-6=1]=6.13, p<.05$ ) showed that adding divorce to a model containing PrePLS4 scores significantly improved model fit. As shown in column five of Table 3, a significant interaction between divorce and prePLS4 scores over time was found; as PrePLS4 scores increased beyond the sample mean, children with divorced parents showed significantly more verbal play episodes than children of married parents, as shown in Figure 3.

A third nested model test (i.e., 5786.19-5781.06 $=5.13 ; \chi^{2}[8-7=1]=5.13, p<.05$ ) showed that the inclusion of the interaction significantly improved model fit. None of the parental education covariates were significantly related to verbal play episodes.

\subsection{APIM Analyses}

The Actor-Partner Interdependence Models (APIM) shown in Equations 4 and 5 were estimated. Results showed a significant partner effect for the relationship between verbal expression and word diversity. Specifically, as the verbal expressions of one child increased, the word diversity of the other child in the dyad significantly increased $\left(\beta_{\text {Partner }}=.28, p<.05\right)$.

\section{Discussion}

The findings from this investigation offer insight to the family-related factors that may influence treatment response to an evidence-based social communication intervention targeting preschoolers in Head Start settings. The results of the positive peer interactions analyses suggested that children from married, separated, or widowed homes tended over time to interact more positively with their peers than children whose parents were divorced. Children whose parents were divorced showed a decrease in positive peer interactions over time. Similar data patterns were found for both the children who were immediate responders and the children who were delayed responders. While the incidence data of divorce cases is low, it is important to examine the consequences of divorce on child outcomes for prevention purposes since early intervention can sometimes prevent complications or more severe child outcomes. Teachers who know a child is experiencing a divorce in the family can work more extensively with this child or refer the child for sessions with a school counselor or social worker. Increases in positive peer interactions were also related to maternal education levels for both the children who were immediate responders and the children who were from the delayed responder groups. Our play verbalization analyses showed that children from married, separated, or widowed homes decreased in their play verbalizations over time. Children from divorced families, however, showed increases in play verbalizations over time despite improvements in standardized language scores. This data pattern was true for children who were immediate and delayed responders.

\subsection{Positive Intervention Effects and Marital Status}

Overall, the analyses of positive peer interactions, play verbalizations, and marital status revealed consistent findings. Children from married, separated, or widowed homes demonstrated more positive effects by participating in the social communication intervention (increases in positive peer interactions, decreases in play verbalizations) than children whose parents had divorced. Other past work has indicated a link between single parent households and social interaction difficulties in children, hypothesizing that this factor may diminish a 
parent's capacity for consistent and involved parenting (Pungello et al., 2010; Westerlund \& Lagerberg, 2008; Wilson et al., 2009). Other past work has not detected significant associations between marital status and compromised language abilities in children (Delgado, Vagi, \& Scott, 2005; Scarborough, Lloyd, \& Barth, 2009).

The effects of divorce on preschool-age children has been well documented by Clarke-Stewart and Brentano (2006) who indicated that preschoolers have the most intense reaction to divorce than children at any other age. These feelings may lead to poor self-esteem and compromised peer relationships in the classroom and later in life (Clarke-Stewart \& Brentano).

One possible explanation for positive intervention effects in children from widowed homes, but not children from divorced homes, may be attributed to economic disparities between the two groups. For example, Bryant (2003) reported that children reared in single-mother families as a result of divorce have significantly lower levels of education, occupational status, and happiness in adulthood than children raised in single-parent families due to the death of one parent. This may be due to significant differences in government support and programs available to the two groups. Widows and widowers may receive pensions, life insurance benefits, and/or Social Security benefits that allow them to maintain their current lifestyle. In contrast, there are limited government programs available to divorced parents.

Another potential explanation for divergent intervention effects in children from divorced homes is the gender differences in children's adjustment to divorce. In the current study, more males participated in the social communication intervention. Although gender was not part of the data analysis plan and only a limited number of participants came from divorced homes, possible explanations for the current study's results are worth mentioning. Previous research has demonstrated that boys experience greater maladjustment at pre-divorce, at the time of divorce, and post-divorce. For example, Block, Block, and Gjerde (1986) reported that boys from divorced homes demonstrated poor impulse control, aggression, and excessive energy prior to the divorce and during the time of divorce while girls did not. Boys were also more likely to be depressed and oppositional several years after their parents' divorce (Guidubaldi, Perry, Cleminshaw, \& McLoughlin, 1983). Given these findings, it is possible that boys from divorced homes need additional social skills training and practice that goes beyond the scope of the current social communication program. Possible intervention target skills needed for this population include emotional regulation skills such as controlling impulsive behavior, coping with stress, and recognition of emotions.

\subsection{Positive Intervention Effects and Maternal Education}

Increases in maternal education were related to increases in positive peer interactions and decreases in play verbalizations over time for both children who were immediate and delayed responders. This finding is not surprising given that maternal education level is often considered the single best predictor of poverty status, cognitive and language stimulation in the home, the quality of the home environment, and nutrition (Bornstein, Hahn, Suwalksky, \& Haynes, 2004). A similar impact has been documented in the area of language and communication (e.g., Hart \& Risley, 1995; Hoff, 2003).

Low maternal education is also associated with poorer family functioning (i.e., inability to share feelings, lack of acceptance, poor attachment, lack of connectedness to each other, inability to make decisions because of misunderstandings) and poor child adjustment (Doyle, Moretti, Brendgen, \& Bukowski, 2003). This poorer family functioning style may lead to children being insecurely attached, more noncompliant with maternal requests and prohibitions, less likely to be successful in problem-solving situations, less adept at eliciting help and support from their mothers when confronted with difficult problems or issues, and less socially competent with their peers (Campbell, 2006; Carlson \& Sroufe, 1995). The adverse effects of low maternal education on children's social development has been well-documented, particularly in the area of peer interaction problems (Eisenberg \& Fabes, 1998; Hughes \& Ensor, 2005). In the current study, the association between low maternal education and poor intervention effects suggests that family experiences influence the nature of children's social development which directly and indirectly shapes children's social interactions with peers. Thus, intervention efforts targeting this population of children should occur at the child-level (e.g., the social communication intervention described in the current study) and at the adult-level. For example, parents might be taught strategies to improve their parent-child relationships and be encouraged to initiate and arrange play dates with other children to enhance their child's peer interactions.

\subsection{Partner Effects}

When examining PLS-4 scores, a partner effect occurred for expressive language scores. As a child's expressive language score increased, their peer partner's expressive language score also increased. Prior evidence suggests the existence of gender differences in the preference for group versus dyadic interaction. For example, several 
studies report that girls prefer dyadic interaction while boys prefer to play in larger groups (Benenson, 1993; Fabes, Martin, \& Hanish, 2003). The reasons for these differences between dyadic or group interaction have not been well explored in the preschool literature. Studies conducted with older children suggest that differences in group dynamics are due to differences in the types of games boys and girls generally play, with boys playing sports that require teams while girls prefer games that require limited numbers of people (Fabes et al., 2003; Maccoby, 1988). Given that boys and girls improved their expressive language scores on the PLS-4, intervention programs targeting dyads seem appropriate for this population of children.

\subsection{Limitations}

Several limitations of this study should be noted. First, these data were collected from primarily white, lower SES children enrolled in Head Start classrooms. As such, the generalizability of the findings may be limited and it is unclear whether different patterns would be found among children from different ethnic groups or in other settings. Second, these data are based on intervention services that were provided as a "pull-out" service delivery model rather than a "pull-in" service delivery model. Pull-out service delivery models have previously been criticized in the literature for isolating target children, for the target children having difficulty generalizing to natural settings, and for the lack of social communication interactions (Paul-Brown \& Caperton, 2001). Future research should focus on the effects of the social communication intervention implemented in the classroom setting during natural routines. Finally, children's peer groups operate in larger social contexts than dyadic interactions. Thus, it will be important to investigate in the future how the effects of the social communication intervention on small groups of children rather than dyadic interactions.

\subsection{Implications}

The present study highlights the impact of family-related factors that may influence treatment response to an evidence-based social communication intervention. The current study extends the research on the vulnerability of children from low-income families with additional risk factors (e.g., children from divorced families or single-parent homes, low maternal education) and the differential outcomes of these risks. The current study highlights the need for multi-level interventions for children who experience multiple risk factors and their families. Early childhood interventions often include parent involvement as a key program component, such as Head Start (U.S. Department of Health and Human Services, Office of Head Start, 2010) and the Infant Health and Development Program (McCormick, McCarton, Brooks-Gunn, Belt, \& Gross, 1998). However, these programs tend to focus on adult self-sufficiency outcomes such as parental education, employment status, and welfare status. While the adult self-sufficiency focus is critical, it does not address improving the parent-child interactions within the home which are equally important to improving children's interactions with peers.

Children who come from divorced homes or have mothers with low maternal education levels may benefit from emotional regulation skills training in addition to the social communication skills training provided in the current intervention program. Some examples of emotional regulation strategies for preschoolers include relationship building, educating children about emotions, and teaching children specific age-appropriate strategies for regulating their emotions (Denham, 1998). Relationship building requires the adult to observe a child during play, commenting on what he or she sees in the play observation, and subsequently following the child's lead with communication during play (Joseph \& Strain, 2003). Along with relationship building, adults can promote children's understanding of emotions by exposing them to feeling words with accompanying pictures, utilizing these feeling words to describe feelings in themselves and others, and recognizing that all emotions have consequences. Finally, the Turtle Technique (Denham, 1998) can be taught to children as a strategy for regulating impulsive emotions. Through this technique, children are taught how to control negative emotions by retreating into their "turtle shell" when they feel anger or hurt in order to calm down. During this calming down time, they think about how to respond appropriately to the situation and then act upon their decision.

\section{Conclusion}

The present findings suggest that the social communication intervention described in the current study is most effective with children who come from married, separated, or widowed families and families with higher levels of maternal education. This was true of both children who were immediate and delayed responders to the intervention. It is important for future work to explore additional intervention needs for children from divorced homes or families with lower maternal education levels. It will be important to explore the teaching of emotional regulation skills in these children as well as teaching parents how to improve the quality of their home environment including the parent-child relationship. 


\section{References}

Achenbach, T. M. (1997). Guide for the Caregiver-Teacher Report Form for ages 2-5. Burlington, VT: University of Vermont, Department of Psychiatry.

Aiken, L.S., \& West, S.G. (1991). Multiple regression: Testing and interpreting interactions. Thousand Oaks, CA: Sage.

Al Otaiba, S. A., \& Fuchs, D. (2002). Characteristics of children who are unresponsive to early literacy intervention. Remedial and Special Education, 23, 300-316. http://dx.doi.org/10.1177/07419325020230050501

Atkins, D. C. (2005). Using multilevel models to analyze couple and family treatment data: Basic and advanced issues. Journal of Family Psychology, 19, 98-110. http://dx.doi.org/10.1037/0893-3200.19.1.98

Benenson, J. F. (1993). Greater preference among females than males for dyadic interaction in early childhood. Child Development, 64, 544-555. http://dx.doi.org/10.2307/1131268

Block, J. H., Block, J., \& Gjerde, P. F. (1986). The personality of children prior to divorce. Child Development, 57, 827-840. http://dx.doi.org/10.2307/1130360

Bornstein, M. H., Hahn, C., Suwalsky, J. T., \& Haynes, O. M. (2004). Socioeconomic status, parenting, and child development: The Hollingshead Four-Factor Index of Social Status and the Socioeconomic Index of Occupations. In M. H. Bornstein \& R. H. Bradley (Eds.), Socioeconomic status, parenting, and child development (pp. 29-82). Mahwah, NJ: Lawrence Erlbaum Associates.

Bryant, C. (2003). Handbook of death and dying (Vol. 1). Thousand Oaks, CA: Sage Publications.

Campbell, J. M., \& Herizinger, C. V. (2009). Statistics and single subject research methodology. In D. L. Gast (Ed.), Single subject research methodology in behavioral sciences. New York, NY: Routledge.

Campbell, S. B. (2006). Behavior problems in preschool children: Clinical and developmental issues ( $2^{\text {nd }}$ ed.). London: The Guilford Press.

Carlson, E., \& Sroufe, L. A. (1995). Contribution of attachment theory to developmental psychopathology. In D. Cicchetti \& D. Cohen (Eds.), Developmental psychopathology: Vol. 1 Theory and methods (pp. 3-20). New York, NY: Wiley.

Carter, E. W., Sisco, L. G., Chung, Y., \& Stanton-Chapman, T. (in press). Peer interactions of students with intellectual disabilities and/or autism: A map of the intervention literature. Research and Practice for Persons with Severe Disabilities.

Chomitz, V. R., Cheung, L. W. Y., \& Lieberman, E. (1995). The role of lifestyle in preventing low birthweight. Future of Children, 5(1), 195-211. http://dx.doi.org/10.2307/1602511

Clarke-Stewart, A., \& Bretano, C. (2006). Divorce: Causes and consequences. New Haven, CT: Yale University Press.

Delgado, C. E. F., Vagi, S. J., \& Scott, K. G. (2005). Early risk factors for speech and language impairments. Exceptionality, 13, 173-191. http://dx.doi.org/10.1207/s15327035ex1303_3

Denham, S. A. (1998). Emotional development in young children. New York, NY: Guilford Press.

Doyle, A. B., Moretti, M. M., Brendgen, M., \& Bukowski, W. (2003). Parent-child relationships and adjustment in adolescence: Findings from the HBSC Cycle 3 and NLSCY Cycle 2 Studies. Montreal, Canada: Centre for Research in Human Development, Concordia University.

Eisenberg, N., \& Fabes, R. A. (1998). Prosocial development. Handbook of child psychology (5th ed., Vol. 3, pp. 701-778). New York, NY: Wiley and Sons.

Enders, C. K., \& Tofighi, D. (2007). Centering predictor variables in cross-sectional multilevel models: A new look at an old issue. Psychological Methods, 12, 121-138. http://dx.doi.org/10.1037/1082-989X.12.2.121

Fabes, R. A., Martin, C. L., \& Hanish, L. D. (2003). Young children's play qualities in same-, other-, and mixed-sex peer groups. Child Development, 74, 921-932. http://dx.doi.org/10.1111/1467-8624.00576

Gast, D. L., \& Spriggs, A. D. (2010). Visual analysis of graphic data. In D. L. Gast (Ed.), Single subject research methodology in behavioral sciences (pp. 199-233). New York, NY: Routledge.

Gresham, F. M., \& Elliott, S. N. (1990). Social Skills Rating System Manual. Circle Pines, MN: American Guidance Service.

Guidubaldi, J., Perry, J. D., Cleminshaw, H. K., \& McLoughlin, C. (1983). The impact of parental divorce on 
children: Report on the nationwide NASP study. School Psychology Review, 12, 300-323.

Hart, B., \& Risley, R. T. (1995). Meaningful differences in the everyday experience of young American children. Baltimore, MD: Brookes.

Hoff, E. (2003). The specificity of environmental influence: Socioeconomic status affects early vocabulary development via maternal speech. Child Development, 74, 1368-1378. http://dx.doi.org/10.1111/1467-8624.00612

Hoff-Ginsberg, E. (1991). Mother-child conversation in different social classes and communicative settings. Child Development, 62, 782-796. http://dx.doi.org/10.2307/1131177

Horner, R. H., Carr, E. G., Halle, J. McGee, G., Odom, S., \& Wolery, M. (2005). The use of single-subject research to identify evidence-based practice in special education. Exceptional Children, 71, 165-179.

Hughes, C., \& Esnor, R. (2005). Theory of mind and executive function in 2-year-olds: A family affair? Developmental Neuropsychology, 28, 645-668. http://dx.doi.org/10.1207/s15326942dn2802_5

Joseph, G. E., \& Strain, P. A. (2003). Comprehensive evidence-based social-emotional curricula for young children: An analysis of efficacious adoption potential. Topics in Early Childhood Special Education, 23, 65-76. http://dx.doi.org/10.1177/02711214030230020201

Kashy, D. A., Donellan, M. B., Burt, S. A., \& McGue, M. (2008). Growth curve models for indistinguishable dyads using multilevel modeling and structural equation modeling: The case of adolescent twins' conflict with their mothers. Developmental Psychology, 44, 316-329. http://dx.doi.org/10.1037/0012-1649.44.2.316

Kenny, D. A., Kashy, D. A., \& Cook, W. L. (2006). Dyadic data analysis. New York, NY: Guilford Press.

Kenny, D. A., \& Ledermann, T. (2010). Detecting, measuring, and testing dyadic patterns in the actor-partner interdependence model. Journal of Family Psychology, 24, 359-366. http://dx.doi.org/10.1037/a0019651

Kratochwill, T. R. Hitchcock, J., Horner, R. H., Levin, J. R., Odom, S. L., Rindskopf, D. M., \& Shadish, W. R. (2010). Single case design technical documentation. [Online] Available: http://ies.ed.gov/ncee/wwc/pdf/wwc_scd.pdf.

Laurenceau, J. P., \& Bolger, N. (2005). Using diary methods to study marital and family processes. Journal of Family Psychology, 19, 86-97. http://dx.doi.org/10.1037/0893-3200.19.1.86

Lopez, M., Tarullo, L., Forness, S., \& Boyce, C. (2000). Early identification and intervention: Head Start's response to mental health challenges. Early Education and Development, 11, 265-282. http://dx.doi.org/10.1207/s15566935eed1103_3

Maccoby, E. E. (1988). Gender as a social category. Developmental Psychology, 24, 755-765. http://dx.doi.org/10.1037/0012-1649.24.6.755

McCormick, M. C., McCarton, C., Brooks-Gunn, J., Belt, P., \& Gross, R. T. (1998). The Infant Health and Development Program: Interim summary. Journal of Developmental and Behavioral Pediatrics, 19, 359-370. http://dx.doi.org/10.1097/00004703-199810000-00009

McMaster, K. L., Fuchs, D., Fuchs, L. S., \& Compton, D. L. (2005). Responding to nonresponders: An experimental field trial of identification and intervention methods. Exceptional Children, 71, 445-463.

Mehta, P. D., \& West, S. G. (2000). Putting the individual back in to individual growth curves. Psychological Methods, 5, 23-43. http://dx.doi.org/10.1037/1082-989X.5.1.23

Missall, K. N., \& Hojnoski, R. L. (2008). The critical nature of young children's emerging peer-related social competence for transition to school. In W. H. Brown, S. L. Odom, \& S. R. McConnell (Eds.), Social competence of young children: Risk, disability, and intervention (pp. 117-137). Baltimore, MD: Brookes.

Paul-Brown, D., \& Caperton, C. J. (2001). Inclusive practices for preschool-age children with specific language impairment. In M. J. Guralnick (Ed.), Early childhood inclusion: Focus for change (pp. 433-463). Baltimore, MD: Brookes Publishing.

Peugh, J. L. (2010). A practical guide to multilevel modeling. Journal of School Psychology, 48, 85-112. http://dx.doi.org/10.1016/j.jsp.2009.09.002

Peugh, J. L., DiLillo, D., \& Panuzio, J. (2011, in press). Analyzing mixed dyadic data using structural equation models. Structural Equation Modeling.

Prizant, B. M., \& Wetherby, A. M. (1998). Understanding the continuum of discrete-trial traditional behavioral to 
social-pragmatic developmental approaches in communication enhancement for young children with autism/PDD. Seminars in Speech and Language, 19, 329-352. http://dx.doi.org/10.1055/s-2008-1064053

Pungello, E. P., Kainz, K., Burchinal, M., Wasik, B. H., Sparling, J. J., Ramey, C. T., \& Campbell, F. A. (2010). Early educational intervention, early cumulative risk, and the early home environment as predictors of young adult outcomes within a high-risk sample. Child Development, 81, 410-426. http://dx.doi.org/10.1111/j.1467-8624.2009.01403.x

Raudenbush, S. W., Brennan, R. T., \& Barnett, R. C. (1995). A multivariate hierarchical model for studying psychological change within married couples. Journal of Family Psychology, 9, 161-174. http://dx.doi.org/10.1037/0893-3200.9.2.161

Raudenbush, S. W., \& Bryk, A. S. (2002). Hierarchical linear models: Applications and data analysis methods (2nd ed.). Newbury Park, CA: Sage.

Reichow, B., \& Volkmar, F. R. (2010). Social skills interventions for individuals with autism: Evaluation for evidence-based practices with a best evidence synthesis framework. Journal of Autism and Developmental Disorders, 40, 149-166. http://dx.doi.org/10.1007/s10803-009-0842-0

Reyno, S. M., \& McGrath, P. J. (2006). Predictors of parent training efficacy for child externalizing behavior problems: A meta-analytic review. Journal of Child Psychology and Psychiatry, 47, 99-111. http://dx.doi.org/10.1111/j.1469-7610.2005.01544.x

Scarborough, A. A., Lloyd, C., \& Barth, R. P. (2009). Maltreated infants and toddlers: Predictors of developmental delay. Journal of Developmental and Behavioral Pediatrics, 30, 489-498. http://dx.doi.org/10.1097/DBP.0b013e3181c35df6

Shadish, W. R., Rindskopf, D. M., \& Hedges, L. V. (2008). The state of the science in the meta-analysis of single-case experimental designs. Evidence-Based Communication Assessment and Intervention, 3, 188-196. http://dx.doi.org/10.1080/17489530802581603

Sherer, M. R., \& Schreibman, L. (2005). Individual behavioral profiles and predictors of treatment effectiveness for children with autism. Journal of Counseling and Clinical Psychology, 73, 525-538. http://dx.doi.org/10.1037/0022-006X.73.3.525

Stanton-Chapman, T. L. (2005). Intervention procedures manual for social communication skills intervention: Preschool version. Unpublished manuscript, University of Virginia, Charlottesville, VA.

Stanton-Chapman, T. L., Denning, C. B., \& Jamison, K. R. (2008). Exploring the effects of a social communication intervention for improving requests and word diversity in preschoolers with disabilities. Psychology in the Schools, 45, 644-664. http://dx.doi.org/10.1002/pits.20315

Stanton-Chapman, T. L., Denning, C. B., \& Jamison, K. R. (2010). Communication skill-building in young children with and without disabilities in a preschool classroom. The Journal of Special Education. http://dx.doi.org/10.1177/0022466910378044

Stanton-Chapman, T. L., Jamison, K. R., \& Denning, C. B. (2008). Teaching social pragmatic skills to young children at-risk. Early Childhood Services: An Interdisciplinary Journal of Effectiveness, 2, 225-251.

Stanton-Chapman, T. L., Kaiser, A. P., Vijay, P., \& Chapman, C. (2008). A multicomponent intervention to increase peer-directed communication in Head Start children. Journal of Early Intervention, 30, 188-212. http://dx.doi.org/10.1177/1053815108318746

Stanton-Chapman, T. L., Kaiser, A. P., Viajay, P., \& Craig-Unkefer, L. (2003). The peer language and behavior code. Unpublished manuscript, Vanderbilt University, Nashville, TN.

Stanton-Chapman, T. L., Kaiser, A. P., \& Wolery, M. (2006). Building social communication skills in Head Start children using storybooks: The effects of prompting on social interactions. Journal of Early Intervention, 28, 197-212. http://dx.doi.org/10.1177/105381510602800307

Stanton-Chapman, T. L., \& Snell, M. E. (in press). Promoting turn-taking skills in preschool children with disabilities: The effects of a peer-based social communication intervention. Early Childhood Research Quarterly.

Tapp, J. (2003). SALTRELY program: Manual for collecting observation data using SALTRELY. Unpublished manuscript, Vanderbilt University, Nashville, TN.

U.S. Department of Health and Human Services, Office of Head Start (2010). Head Start program description. [Online] Available: http://www.acf.hhs.gov/programs/ohs/about/index.html\#prog_desc (October 18, 2010) 
Van den Noortgate, W., \& Onghena, P. (2003). Combining single-case experimental data using hierarchical linear models. School Psychology Quarterly, 18, 325-346. http://dx.doi.org/10.1521/scpq.18.3.325.22577

Westerlund, M., \& Lagerberg, D. (2008). Expressive vocabulary in 18-month children in relation to demographic factors, mother and child characteristics, communication styles, and shared reading. Child: Care, Health, and Development, 34, 257-266. http://dx.doi.org/10.1111/j.1365-2214.2007.00801.x

Wilson, M. N., Hurtt, C. L., Shaw, D. S., Dishion, T. J., \& Gardner, F. (2009). Analysis and influence of demographic and risk factors on difficult child behaviors. Prevention Science, 10, 353-365. http://dx.doi.org/10.1007/s11121-009-0137-x

Zimmerman, I. L., \& Pond, R. E. (2002). Preschool Language Scale-4, revised. Columbus, OH: Merrill.

Table 1. Descriptive statistics

\begin{tabular}{|c|c|}
\hline & $N$ \\
\hline $\begin{array}{l}\text { Male } \\
\text { Female }\end{array}$ & $\begin{array}{l}32 \\
14 \\
\end{array}$ \\
\hline $\begin{array}{l}\text { White } \\
\text { Black } \\
\text { Hispanic } \\
\text { Asian }\end{array}$ & $\begin{array}{l}31 \\
11 \\
4 \\
0\end{array}$ \\
\hline $\begin{array}{l}\text { Employment: } \\
\text { Working Part-Time } \\
\text { Working Full-Time } \\
\text { Unemployed } \\
\text { Looking for Employment } \\
\text { Laid Off } \\
\text { In Military } \\
\text { Part-Time Student } \\
\text { Full-Time Student } \\
\text { Vocational Training Program } \\
\end{array}$ & $\begin{array}{l}4 \\
18 \\
1 \\
9 \\
3 \\
2 \\
4 \\
1 \\
4\end{array}$ \\
\hline $\begin{array}{l}\text { Disability: } \\
\text { Behavior Disorder } \\
\text { Specific Language Impairment } \\
\text { Developmental Delay } \\
\text { Other Disability } \\
\text { No Disability }\end{array}$ & $\begin{array}{l}2 \\
16 \\
17 \\
1 \\
10\end{array}$ \\
\hline $\begin{array}{l}\text { Marital Status: } \\
\text { Single } \\
\text { Married } \\
\text { Divorced } \\
\text { Widowed } \\
\text { Separated } \\
\end{array}$ & $\begin{array}{l}0 \\
37 \\
2 \\
4 \\
3\end{array}$ \\
\hline $\begin{array}{l}\text { Maternal Education: } \\
\text { Less than High School } \\
\text { High School } \\
\text { Some College/Associates } \\
\text { College }\end{array}$ & $\begin{array}{l}9 \\
18 \\
2 \\
17\end{array}$ \\
\hline
\end{tabular}


Table 2. Positive peer interaction model summaries

\begin{tabular}{|c|c|c|c|c|c|}
\hline Parameters & $\begin{array}{l}\text { Time } \\
\text { Fixed } \\
\text { Effect }\end{array}$ & $\begin{array}{l}\text { Time Random } \\
\text { Effect }\end{array}$ & $\begin{array}{l}\text { Quadratic } \\
\text { Time }\end{array}$ & $\begin{array}{l}\text { Parental } \\
\text { Marital }\end{array}$ & $\begin{array}{l}\text { Parental Marital } \\
\text { \& Educational }\end{array}$ \\
\hline & \multicolumn{5}{|c|}{ Regression Coefficients (Fixed Effects) } \\
\hline Intercept & $4.20 * *$ & $4.10 * *$ & $2.29 *$ & $2,34^{*}$ & 1.39 \\
\hline Time & $0.31 * *$ & $0.33 * *$ & $0.82 * *$ & $0.81 * *$ & $0.59 * *$ \\
\hline Time $^{2}$ & -- & -- & $-0.02 * *$ & $-0.02 * *$ & $-0.02 * *$ \\
\hline Single & -- & -- & -- & $-1.67 * *$ & $-1.41^{*}$ \\
\hline Separated & -- & -- & -- & $1.87 * *$ & $1.53^{*}$ \\
\hline Divorced & -- & -- & -- & 2.16 & 0.40 \\
\hline Widowed & -- & -- & -- & $-1.45^{*}$ & -2.99 \\
\hline Widowed*Time & -- & -- & -- & $0.29 *$ & $0.37 * *$ \\
\hline Divorced*Time & -- & -- & -- & -0.24 & -0.21 \\
\hline Some High School & -- & -- & -- & -- & $2.78^{*}$ \\
\hline High School Diploma & -- & -- & -- & -- & 0.76 \\
\hline College Credits & -- & -- & -- & -- & 0.94 \\
\hline High School Diploma*Time & -- & -- & -- & -- & $0.31 * *$ \\
\hline \multirow[t]{2}{*}{ College Credits*Time } & -- & -- & -- & -- & $0.24 * *$ \\
\hline & \multicolumn{5}{|c|}{ Variance Components (Random Effects) } \\
\hline CS Variance & $19.88^{* *}$ & $19.88^{* *}$ & $19.88^{* *}$ & $18.85^{* *}$ & $17.59^{* *}$ \\
\hline CS Covariance & $6.87^{* *}$ & $4.72 * *$ & $4.22 * *$ & $4.69^{* *}$ & $5.34 * *$ \\
\hline Intercept Variance & $14.58^{* *}$ & $12.18 * *$ & $10.51^{* *}$ & $12.37 * *$ & $10.86^{* *}$ \\
\hline Slope Variance & -- & $0.06^{*}$ & $0.05^{*}$ & $0.05^{*}$ & $0.03 *$ \\
\hline \multirow[t]{2}{*}{ Intercept/ Slope Covariance } & -- & -0.17 & -0.02 & -0.03 & 0.11 \\
\hline & \multicolumn{5}{|c|}{ Model Summary } \\
\hline Deviance Statistic & 5461.88 & 5429.37 & 5412.48 & 5388.24 & 5352.79 \\
\hline Estimated Parameters & 5 & 7 & 8 & 14 & 19 \\
\hline
\end{tabular}

Note: $\mathrm{CS}=$ Compound Symmetry, $=\mathrm{p}<.06 ; *=\mathrm{p}<.05 ; * *=\mathrm{p}<.01$ 
Table 3. Verbal play model summaries

\begin{tabular}{|c|c|c|c|c|}
\hline Parameters & Time & Child Covariates & Parent Marital & Interaction \\
\hline & \multicolumn{4}{|c|}{ Regression Coefficients (Fixed Effects) } \\
\hline Intercept & $9.57^{* *}$ & $9.54 * *$ & $9.46^{* *}$ & $9.47 * *$ \\
\hline Time & $-0.40 * *$ & $-0.40 * *$ & $-0.40 * *$ & $-0.40 * *$ \\
\hline PrePLS4 & & $-0.04 *$ & $-0.06^{*}$ & $-0.06^{*}$ \\
\hline Divorce & & & $2.47 *$ & -0.81 \\
\hline \multirow[t]{2}{*}{ Divorce*PrePLS4 } & & & & $1.22 *$ \\
\hline & \multicolumn{4}{|c|}{ Variance Components (Random Effects) } \\
\hline CS Variance & $38.40^{* *}$ & $37.71 * *$ & $37.33^{* *}$ & $37.02 * *$ \\
\hline CS Covariance & -0.42 & -0.07 & 0.12 & 0.28 \\
\hline \multirow[t]{2}{*}{ Intercept Variance } & $12.98^{* *}$ & $14.55^{* *}$ & $13.49 * *$ & $12.63 * *$ \\
\hline & \multicolumn{4}{|c|}{ Model Summary } \\
\hline Deviance Statistic & 5797.79 & 5792.32 & 5786.19 & 5781.06 \\
\hline Estimated Parameters & 5 & 6 & 7 & 8 \\
\hline
\end{tabular}

Note: $\mathrm{CS}=$ Compound Symmetry, ${ }^{*}=\mathrm{P}<.05 ; * *=\mathrm{p}<.01$

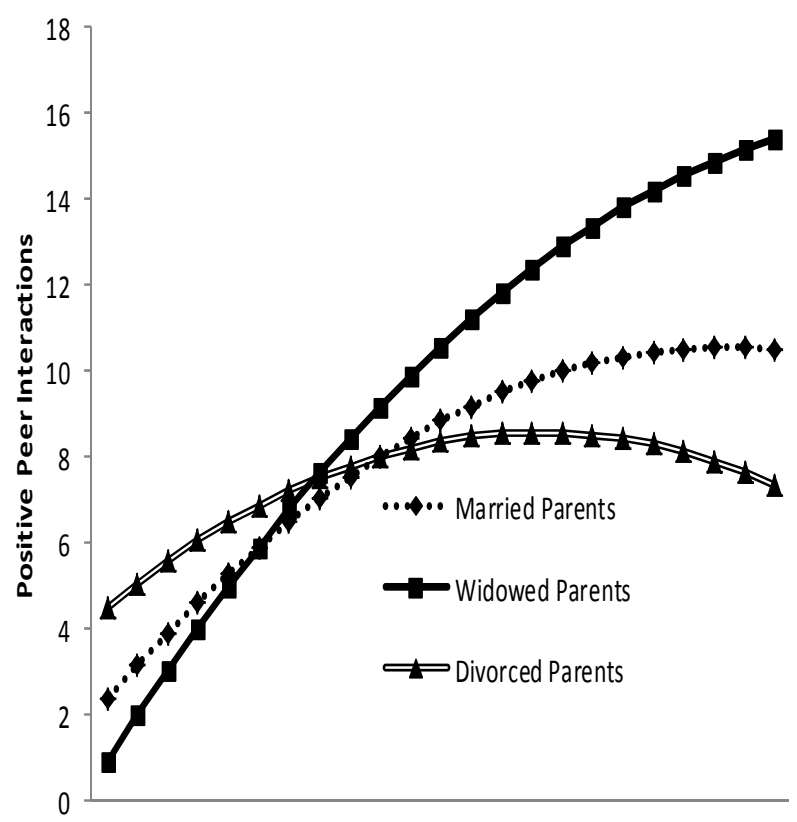

0123345678910111213141516171819202122

Centered Time

Figure 1. Effect of marital status on positive peer interactions 


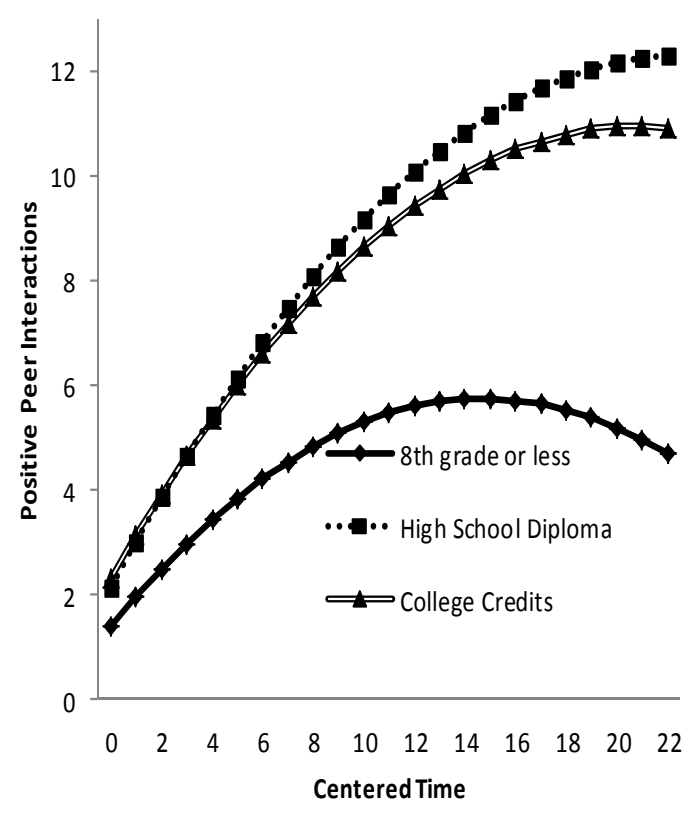

Figure 2. Effect of parental education on positive peer interactions

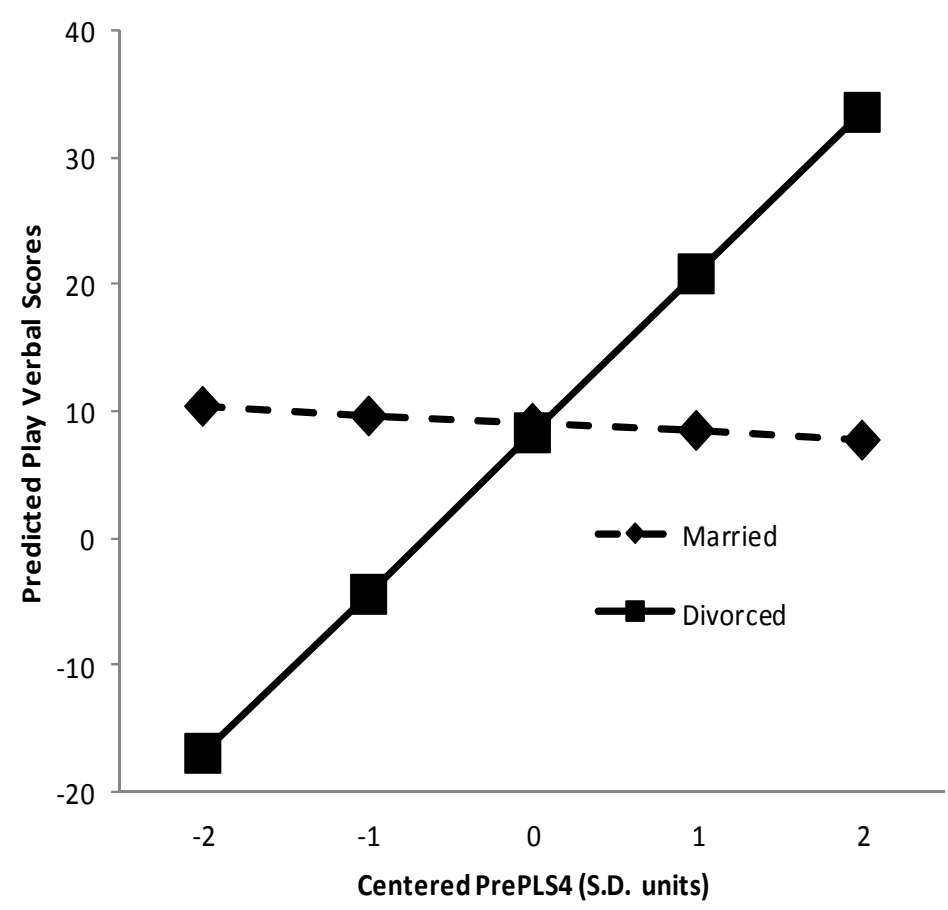

Figure 3. Actor-partner interdependence model (PrePLS4 * Marital Status) interaction 


\section{Appendix: Data Analytic Strategy Expanded}

As stated previously, children were paired into dyads based on several important socioeconomic, demographic, and individual achievement characteristics prior to observational testing. For analysis purposes, the dyads were treated as indistinguishable (see Kenny, Kashy, \& Cook, 2006), meaning that, after matching children on the aforementioned descriptive characteristics prior to assessment, no other variable relevant to the research question could meaningfully distinguish "child \#1" from "child \#2" within a given dyad (Peugh, DiLillo, \& Panuzio, 2011) for all child participants in the sample. A researcher might reasonably assume under these design conditions that three sources of response variable variation require proper multilevel modeling: (1) variation in repeated response variable scores nested within individuals (Level-1), (2) variation in average response variable scores among individual members nested within dyads (Level-2), and (3) variation in mean response variable scores across all dyads (Level-3). However, as described below, longitudinal data sampled from dyads treated as indistinguishable is appropriately modeled with a two-level longitudinal HLM.

As shown elsewhere (Kashy, Donellan, Burt, \& McGue, 2008), properly modeling indistinguishable dyad response variable variation requires that certain longitudinal model parameter estimates (e.g., means and variances) be constrained to equality between the two individuals in a given dyad. Further, if dyads are treated as indistinguishable in multilevel analyses, there is no need for additional HLM subscript notation that differentiates "person \#1" and "person \#2" within each dyad because indistinguishable dyad members would not be expected to differ in their response variable mean or variance estimates by definition. Said differently, a three-level HLM would not be needed to model indistinguishable dyad data because variation between individuals within dyads (i.e., Level-2) would equal zero. Kashy, et al. (2008) refer to this fact as "the heart of the indistinguishability issue (p. 320)." As shown in the HLM Level-1 equation (Equation 1 reprinted below), the generic subscript $i$ is all that is needed to refer to either member of an indistinguishable dyad.

$$
Y_{\text {tid }}=\beta_{0 i d}+\beta_{1 i d}\left(\text { Time }_{\text {tid }}-1\right)+\varepsilon_{\text {tid }}
$$

As also shown elsewhere (Kashy, Donellan, Burt, \& McGue, 2008; Kenny, Kashy, \& Cook, 2006), properly modeling the Level-1 residuals $\left(\varepsilon_{t i d}\right)$ for dyads treated as indistinguishable requires a compound symmetric covariance matrix (i.e., COVTYPE [CS]) in SPSS, as shown below using a simplified three assessment time points $(t=3)$ example.

$$
\begin{gathered}
\text { Time } 1 \\
{\left[\begin{array}{ccc}
\sigma_{1}^{2}+\sigma^{2} & \text { Time } 2 & \text { Time } 3 \\
\sigma & \sigma_{1}^{2}+\sigma^{2} & \sigma \\
\sigma & \sigma & \sigma_{1}^{2}+\sigma^{2}
\end{array}\right]}
\end{gathered}
$$

As shown above, a compound symmetric error covariance matrix assumes that response variable variation (main diagonal elements) at each time point for both members of an indistinguishable dvad is an additive constant consisting of response variable variation at time 1 plus residual variation $\left(\sigma_{t=1}^{2}+\sigma^{2}\right)$. As a result, response variable covariances $(\sigma)$ are constant across time; these covariances model the likely highly correlated responses within dyads conditional on time.

The Leve1-2 model aggregates over indistinguishable $i$ individuals within dyads to allow growth trajectory intercept $\left(\gamma_{00}\right)$ and slope $\left(\gamma_{10}\right)$ variation $\left(u_{0 d}, u_{I d}\right)$ across dyads.

$$
\begin{aligned}
& \beta_{0 i d}=\gamma_{00}+u_{0 d} \\
& \beta_{1 i d}=\gamma_{10}+u_{1 d}
\end{aligned}
$$

Further, the Level-2 covariance matrix that modeled intercept $\left(\operatorname{VAR}\left[u_{0 d}\right]=\tau_{00}\right)$ and slope $\left(\operatorname{VAR}\left[u_{1 d}\right]=\tau_{11}\right)$ variance, as well as intercept-slope covariance $\left(\operatorname{COV}\left[\left(u_{0 d}, u_{I d}\right)\right]=\tau_{01}\right)$ was specified as an unstructured (i.e., COVTYPE [UN]) in SPSS as shown below.

$$
\left[\begin{array}{ll}
\tau_{00} & \tau_{01} \\
\tau_{01} & \tau_{11}
\end{array}\right]
$$

The Level-2 covariance $\left(\tau_{01}\right)$ estimate, and its respective significance test, can be used to determine, for example, whether initial response variable $\left(\gamma_{00}\right)$ estimates influence changes in response variable scores $\left(\gamma_{10}\right)$ over time among dyads treated as indistinguishable.

Finally, as an aside, it is noteworthy to mention that several researchers have called into question the appropriateness and utility of a 3-level HLM with data sampled from dyads treated as distinguishable (Laurenceau \& Bolger, 2005). More specifically, researchers have noted that if dyads were treated as distinguishable (e.g., traditional marital dyads), the variation in response variable scores from individuals within 
dyads (i.e., Level-2) within a three level HLM would be non-zero. However, only two degrees of freedom (i.e., two individuals per dyad) would be available by definition, meaning that only one random effect could be estimated at Level-2. Further, other researchers have observed that, if code variables that indicate the role of a particular dyad member (e.g., "husband" or "wife) are included in an HLM, no additional variation exists to be explained at Level-2 (Atkins, 2005). For these reasons, two-level HLMs for analyzing data from dyads treated as distinguishable have been described elsewhere (e.g., Raudenbush, Brennan \& Barnett, 1995). 